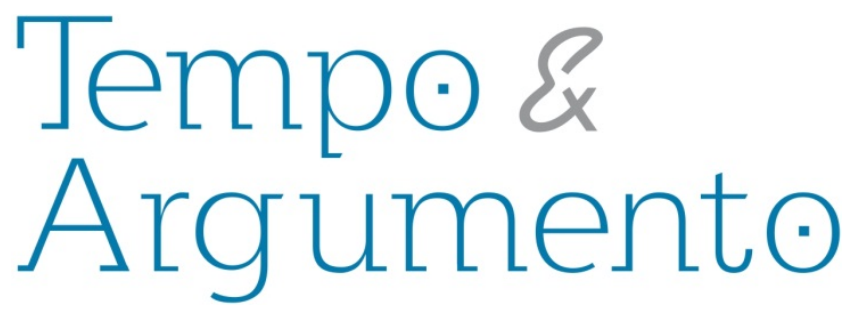

\title{
Raul Pederneiras viajante: as transformações da década de 1920 através do livro Nós pelas costas: notas soltas de um caderno de viagem ${ }^{1}$
}

\begin{abstract}
Resumo
Este artigo analisa a obra de Raul Pederneiras, Nós pelas costas: notas soltas de um caderno de viagens, objetivando demonstrar como o seu autor, figura célebre do Rio de Janeiro no início do século XX, quase chegando aos cinquenta anos de idade e em meio à crise da belle époque carioca, ressignificou o seu Rio de Janeiro, através da sua viagem à Europa entre os anos de 1927 e 1928, utilizando para tal a ótica do humor. Partimos da hipótese de que Raul Pederneiras não foi somente fazer uma viagem como observador da sociedade e das cidades europeias, mas também foi procurar nas suas capitais, notadamente Paris e Roma, explicações para as transformações políticas e intelectuais da década de 1920, como as diversas alternativas de modernidade, a crise da política da Primeira República brasileira e a ascensão dos regimes autoritários na Europa. Nesse caso, consideramos que a viagem de Raul Pederneiras foi uma experiência política na urbe, apresentada ao público através de um exercício da escrita de si.
\end{abstract}

Palavras-chave: Rio de Janeiro - História; PEDERNEIRAS, Raul Paranhos - 1874-1953 - Autobiografia; Humor, Narrativas.

\section{Pedro Krause Ribeiro}

Doutorando em História pela Universidade Federal do Rio de Janeiro. Professor efetivo do Departamento de História do Colégio Pedro II. Brasil pkrause8@yahoo.com.br

\section{Para citar este artigo:}

RIBEIRO, Pedro Krause. Raul Pederneiras viajante: as transformações da década de 1920 através do livro Nós pelas costas: notas soltas de um caderno de viagem. Revista Tempo e Argumento, Florianópolis, v. 8, n. 18, p. 157 -184. maio/ago. 2016.

DOI: $10.5965 / 2175180308182016157$

http://dx.doi.org/10.5965/2175180308182016157

\footnotetext{
${ }^{1}$ Pesquisa feita com auxílio de bolsa de doutoramento concedida pela CAPES. Versão modificada do quinto capítulo da minha tese, ainda em produção, Um figurão da República das Letras: Raul Pederneiras - sua (auto)biografia, sua singularidade e seus trocadilhos. Pesquisa em andamento na Universidade Federal do Rio de Janeiro.
} 


\title{
Raul Pederneiras traveler: the transformations of the 1920's through the book Nós pelas costas: notas soltas de um caderno de viagem [roughly: We, from the back: sparse appointments from a travel notebook]
}

\begin{abstract}
This paper looks into Raul Pederneira's book Nós pelas Costas: notas soltas de um caderno de viagens [roughly: We, from the back: sparse appointments from a travel notebook], trying to show how the author, a famous character from the early twentieth century Rio, almost fifty years old, resignified Rio de Janeiro using his travel to Europe in 1927/28, applying a humorous look. We believe Raul Pederneiras was not simply observing European society and cities, but went to the capitals, mainly Paris and Rome, looking for ways to explain political and intellectual changes of the 1920s. Trying to understand the alternatives to modernity, the political crisis of Brazilian Republic, and the emergence of authoritarian regimes, Pederneiras had a political experience in the city, presented to his readers as an exercise of autobiographical writing.
\end{abstract}

Keywords: Rio de Janeiro - History; PEDERNEIRAS, Raul Paranhos - 1874-1953 - Autobiography; Humor, Narratives. 


\section{Introdução}

Raul Pederneiras foi uma figura célebre da belle époque carioca. Nascido no Rio de Janeiro, em 15 de agosto de 1874, Raul estudou no Colégio Pedro II e formou-se pela Faculdade Livre de Direito do Rio de Janeiro, em 1896. Em sua trajetória profissional, além de reconhecido caricaturista, foi professor da própria Faculdade de Direito e da Escola Nacional de Belas Artes. Dentre as várias associações das quais fez parte, Raul foi membro da Academia Carioca de Letras, presidente da Associação Brasileira de Imprensa (ABI), fundador da Sociedade Brasileira de Autores Teatrais (SBAT) e um dos fundadores do Grêmio Carioca, instituição que agia politicamente na promoção e defesa da memória da cidade do Rio de Janeiro. Raul morreu no dia 11 de maio de $1953 .{ }^{2}$

Por figura célebre, entendemos que Raul Pederneiras era um indivíduo ilustre, como um sujeito que construiu uma reputação de um "virtuoso", tal qual pontua Paul Metzner (1998) na análise que faz da sociedade parisiense da Era das Revoluções. Segundo o autor, entre o último quarto do século XVIII e a primeira metade do século XIX, observou-se em Paris o surgimento de um grupo de indivíduos considerados "virtuosos", que seriam aqueles que apresentariam grande habilidade técnica em alguma arte, ou ofício, e que, necessariamente, exibiam esses talentos para uma audiência, procurando com tal exposição pública certa reputação e prosperidade, através de uma constante conquista de audiências. Para o autor, os virtuosos tinham uma inclinação teatral e amavam "performar" (METZNER, 1998, p. 1-12).

Nesse sentido, Raul era um "virtuoso", porém no contexto da belle époque carioca do início do século XX. Na rua, nos jornais, na academia ou na Associação Brasileira de Imprensa, Raul Pederneiras fazia da performance a possibilidade de se promover, tornando célebre o seu tipo e o seu nome. Raul fez parte de uma boemia literária que tinha dois eixos de publicação e construção de prestígio: a imprensa e a vida social; grupo para o qual o recolhimento e a contemplação eram substituídos pela performance da vida social agitada (LUSTOSA, 1993, p. 36-37).

\footnotetext{
${ }^{2}$ Para um panorama da vida de Raul Pederneiras ver Herman Lima (1963, p. 988-1012).
} 
A construção da virtuosidade de Raul Pederneiras é semelhante ao que ocorre à figura de Jean-Jacques Rousseau, analisada por Antoine Lilti (2014), para quem, somente nas condições sociais da Paris do final do século XVIII, poderia aparecer um indivíduo como Rousseau, que buscava mecanismos de reconhecimento público. Para Lilti (2008, p. 55), Rousseau estava inserido em um novo regime de celebridade no qual o nome próprio tinha um papel primordial, pois era através do nome do autor que se remetia à obra, marcando a sua identidade social, tornando-o notado, célebre para pessoas que não o conheciam pessoalmente.

Tal figura célebre, como a de Raul, além de se fazer presente nos grandes jornais e revistas, apresentando-se para ser reconhecido, acabava por ser transpassada pelas instituições políticas, deixando registros sobre a escrita de si e as reflexões tecidas por conta das diversas mudanças vividas. No caso de Raul Pederneiras, enquanto estudante, viu no Colégio Pedro II a proclamação da República, em 1889; como presidente da ABI, participou politicamente de momentos como a crise oligárquica da década de 1920; como diretor da Faculdade de Direito, questionou as nomeações feitas pelo governo provisório de 1930; e durante o Estado Novo, foi obrigado a optar por um dos cargos do magistério, pois a lei não Ihe permitia conjugar as Belas Artes com o Direito.

$\mathrm{Na}$ virada dos quarenta para os cinquenta anos de idade, Raul Pederneiras experimentaria a crise e as transformações intelectuais da década de 1920 do Brasil e do mundo pós-Primeira Guerra. De fato, como toda a intelectualidade boêmia do Rio de Janeiro, já mapeada pela historiografia, Raul fez parte de um grupo de "intelectuais humoristas" que utilizavam o cotidiano e a rua para pensar e repensar a modernidade e a nacionalidade (LUSTOSA, 1993; VELLOSO, 2015). Segundo Laura Nery (2000), especificamente sobre a obra de Raul Pederneiras, as suas caricaturas e crônicas eram um relato etnográfico, uma verdadeira "cartilha" da modernidade, possuindo um caráter antropológico.

E esse artista moderno, cuja narrativa etnográfica tem na experiência da urbe uma importância única, ressignificou o seu Rio de Janeiro e a si próprio, através de uma viagem que fez à Europa, entre 1927 e 1928, procurando nas capitais europeias, com destaque para as estadias em Paris e Roma, explicações para as transformações políticas 
e intelectuais da década de 1920, como as diversas alternativas de modernidade, a crise da política oligárquica da Primeira República e a ascensão dos regimes autoritários na Europa, como o fascismo de Mussolini. ${ }^{3}$

Suas impressões políticas e de viagens encontram-se no livro Nós pelas costas: notas de um caderno de viagem, publicado em 1930, pela Tipografia do Jornal do Brasil, empresa na qual Raul Pederneiras trabalhou por quase toda a vida, seja no Jornal do Brasil ou na Revista da Semana, publicando charges, caricaturas, poemas e prosas. Em formato 22X15,5 cm, o livro tem 70 páginas, permeadas por textos e ilustrações, identificadas pelo autor como "calungas", portanto, "bonecos" caricaturescos. Cabe ressaltar que o livro foi fruto de apresentações de Raul Pederneiras em palestras e que trechos dele também foram publicados no Jornal do Brasil. Logo, era parte de uma estratégia mais ampla de atuação política de Raul e mais uma forma de autopromoção de sua figura célebre. É sobre essa obra e as impressões de Raul com relação às mudanças políticas e intelectuais da década de 1920 que ora nos deteremos.

\section{Raul Pederneiras pelas costas: do Rio de Janeiro para a Europa.}

A capa do livro de Raul Pederneiras é um convite ao livro. O título e a ilustração da capa são envolvidos por uma molduragem (Figura 1). O intuito da moldura na ilustração da capa é o de simular uma fotografia. O autor se autocaricatura junto ao fiel cachorro figura marcante de sua obra -, e os dois estão vestidos para uma viagem quase etnográfica à Europa. Do corpo alto e magro de Raul Pederneiras pouco se mostrava por conta das pesadas roupas de frio que vestia, sobressaltando somente os seus notáveis bigodes, marcas da sua autoconstrução. O chapéu de abas largas, outra característica de sua composição como personagem, também aparece na autocaricatura, porém sem a cor predominantemente preta; talvez para, graficamente, não fazer desaparecer os bigodes, que pela falta de contorno poderiam se misturar ao chapéu.

\footnotetext{
${ }^{3}$ Sobre a intelectualidade na década de 1920 e a relação das suas produções com a crise do pós- Guerra e do contexto da crise oligárquica brasileira, ver, entre outros, os estudos de Lahuerta (2002) e de Oliveira (1990).
} 


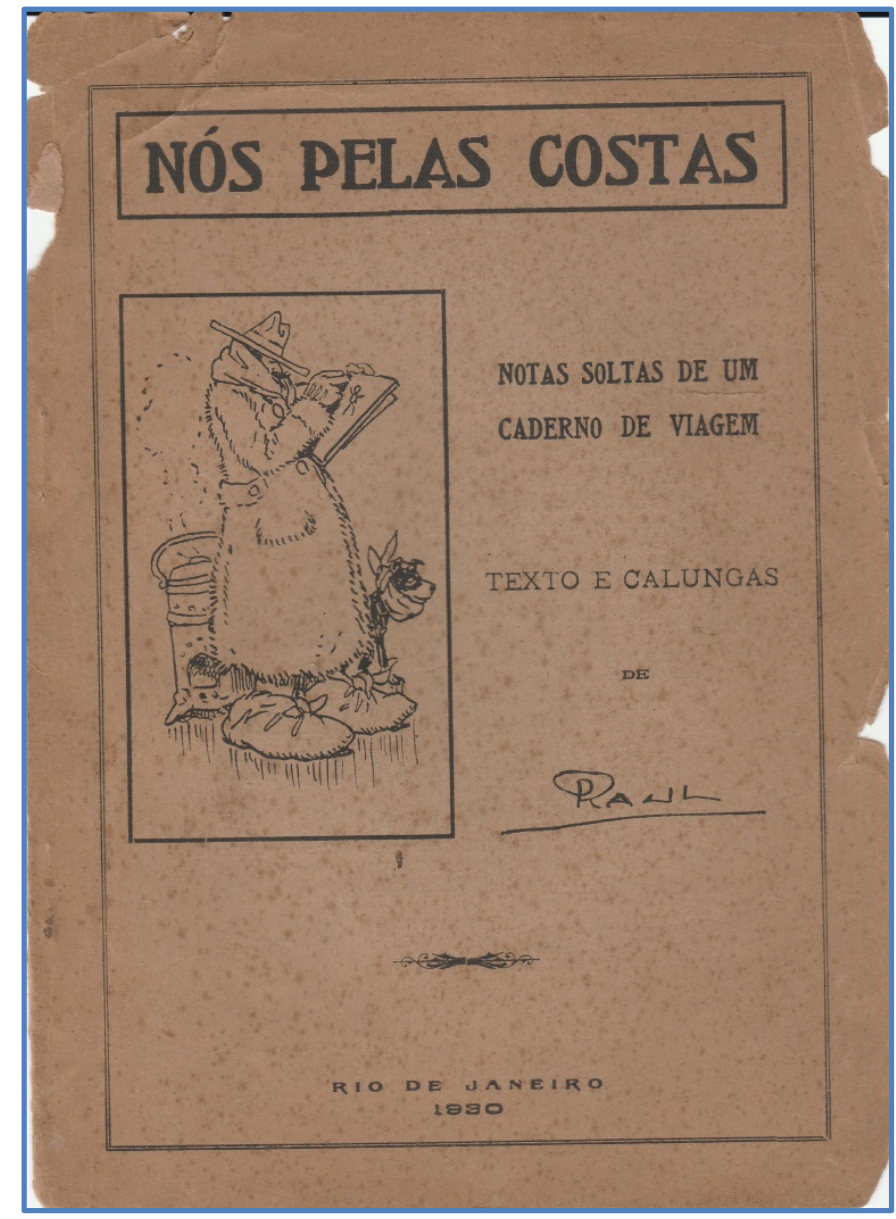

Figura 1. Legenda: Capa do livro Nós pelas Costas.

Referência: PEDERNEIRAS, Raul. Capa de Nós pelas costas. 1930. 1 ilustração. Acervo pessoal.

$\mathrm{Na}$ capa, em tom de metalinguagem, Raul Pederneiras se autocaricatura desenhando em uma folha de papel. O "boneco" que faz de si é uma brincadeira com os instantâneos tão amplamente divulgados na imprensa ilustrada do início do século XX. A contextualização da obra, parte de sua performance perante o público leitor, é facilmente identificável: as roupas de frio, o aquecedor portátil e o cachorro, que para se proteger das baixas temperaturas europeias recebe alguns panos amarrados à cabeça e às patas.

O mesmo tipo de pano protege os pés de Raul Pederneiras do frio. No entanto, o tamanho do acolchoado é proporcionalmente maior do que o seu corpo, o que é cômico. Raul Pederneiras se coloca como um calunga dentro do seu próprio livro, não deixando dúvidas de se tratar de uma obra humorística. A assinatura típica de suas caricaturas, com o "erre" sobrepondo-se ao "pê", de Raul Pederneiras, atesta a autoria do humorista e não do professor doutor das universidades. É, portanto, um livro da figura célebre Raul 
Pederneiras. Apesar de ser uma obra humorística, o texto possui em si elementos autorreferenciais e opiniões sobre as transformações políticas e sociais pelas quais passava o Brasil da década de 1920, tendo, portanto, um forte caráter político.

O autor partia à Europa em busca de respostas para as transformações políticas brasileiras e no intuito de recriar um sentido para as mudanças ocorridas na cidade do Rio de Janeiro, que já não era a da belle époque, que antes era incluída no cosmopolitismo cujas referências eram europeias (MACHADO NETO, 1973, p. 58-62); mas que sofria na década de 1920 com uma forte influência norte-americana e com as intervenções de um modernismo diferente do dos anos iniciais da República, colocando para o autor um dilema, que só seria possível de ser respondido com a sua viagem à Europa, em especial às suas cidades-capitais ideais, Paris e Roma.

O livro de Raul Pederneiras, ainda nas suas primeiras páginas, destaca a ligação do autor com a cidade do Rio de Janeiro e o sentimento da partida da capital da República. A paisagem observada por Raul Pederneiras era a da metrópole, dando "ecos luminosos" ao viajante:

Olhamos para a avenida Rio Branco, miramos a baía circundada pelo colar de luzes, que lacrimejavam sobre as águas mansas... A cidade chamavanos; como um sonâmbulo íamos descer, voltar a terra firme... Olhamos de novo para o cais; já estava longe, mal desenhado na escuridão da noite... Fora da barra ainda nos comovia o afastamento; a saudade, o sentimento que é tão nosso, começou a afligir-nos... As montanhas fugiam aos nossos olhos... Somente uma nesga de praia, um nimbo de luzes, em Copacabana, com os ecos luminosos dos derradeiros adeuses... (PEDERNEIRAS, 1930, p.6)

Observa-se pelo texto de Raul que o bairro de Copacabana já recebia um contingente populacional maior do que o do início do século XX. Ainda assim, eram poucas as suas luzes, um último adeus que o autor dava à terra carioca, antes do sopor em que mergulharia ao desbravar a Europa em busca de respostas às inquietudes que sentia. Raul Pederneiras deixava para trás a Avenida Rio Branco, "obra-síntese" da belle époque no Brasil (OLIVEIRA, 1990, 111). 
O seu sentimento de amargura é apontado pelo lacrimejar das luzes na baía de Guanabara. A noite e o sono faziam Raul Pederneiras misturar dois sentimentos: o de deixar a cidade, sua íntima companheira, e o de desvendar o próprio crescimento da capital. A complexidade de vivenciar a cidade: as luzes de Copacabana que marcam o último adeus, este é também um dos motivos de suas angústias e a estratégia de buscar na Europa as suas respostas. Essa busca já é destacada nas páginas iniciais da obra, quando Raul (PEDERNEIRAS, 1930, p. 5) indica as suas expectativas ao se lançar rumo à Europa:

Depois de longo platonismo, com o pensamento a viajar à volta do mundo, anos seguidos, através dos livros e das imagens, tivemos o arrojo de uma excursão pelo velho continente, com a ajuda de magro orçamento, cheio de muita vontade, mas quase vazio de numerário. Faltou-nos o comodismo oficial das comissões folgadas, mas tivemos de sobra energia e vontade, aliadas ao trabalho intenso.

Raul se colocava como um simples trabalhador que, sem as pompas do oficialato, conseguia viajar "ao mundo", que, no seu caso, era a Europa.

O título deste caderno de viagens, Nós pelas costas, é marcado pelos trocadilhos tão presentes na obra de Raul Pederneiras. Em Geringonça carioca, dicionário de gírias do autor, há o verbete "Nós", com a entrada "Cheio de nós pelas costas". Segundo Raul Pederneiras (1946, p. 47), na gíria utilizada pelos cariocas, estar com “nós pelas costas” significava: "Nós (Cheio de -) - Embaraçado. Cheio de nós pelas costas: assustado, atrapalhado." A expressão, além de “embaraçado, assustado e atrapalhado", também era utilizada para indicar uma pessoa de temperamento difícil. ${ }^{4}$

Seguindo somente o significado descrito por Raul Pederneiras, o título de seu livro indica algumas interpretações possíveis. Primeiro uma compreensão literal do título, que seria a do próprio Raul e sua esposa, Vanda, navegando através da costa dos continentes americano e europeu, logo "nós [o casal] pelas costas". Outra, mais ou menos literal, é a

\footnotetext{
${ }^{4}$ Por exemplo, um texto sobre o ator norte-americano James Cagney o descreve como: “[...] um homem genial, porém, cheio de complicações, ou como diria o outro "cheio de nós pelas costas"”. Ver: Correio Paulista, 12/03/1936, p. 7.
} 
da interpretação da ilustração da capa: Raul e o seu cachorro passeando pela Europa, observando hábitos e costumes da população do velho continente, com uma verve humorística daquela sociedade.

Outra interpretação possível para o título é pela sugestiva possibilidade de, ao chegar à Europa, saber como o Brasil era conhecido no velho continente, como ocorre quando Raul Pederneiras (1930, p. 16-18) discorre sobre as troças que praticou com alguns estrangeiros que não sabiam onde era o Brasil, perguntando-lhe sobre animais silvestres que andavam entre as pessoas e sobre a língua falada no país. "Nós pelas costas", nesse caso, seria uma análise in loco de um intelectual da belle époque sobre a eficácia ou não de toda uma tentativa de se construir uma imagem de um Brasil civilizado na Europa.

Por fim, a explicação da própria gíria “nós pelas costas” presente em Geringonça carioca, de um Raul "assustado" e "embaraçado" com o que imaginava da Europa, com o que encontrara por lá. Das cidades "idealizadas" para as cidades "reais". O choque se dará principalmente com Paris, que não corresponderá absolutamente em nada com a sua expectativa. Nesse caso, Raul "cheio de nós pelas costas" comprovaria, através de sua leitura humorística do mundo, o colapso de uma determinada civilização, para citarmos Alceu Amoroso Lima (1973, 55-56 apud OLIVEIRA, 1990, 118).

O escritor Terra de Senna fez uma interpretação parecida do título, destacando estar no trocadilho (do título e de todo o texto) aquilo que "personaliza" o trabalho do “querido e popular caricaturista”. Segundo o autor (SENNA, 04/07/1931, p. 6), esse é o livro de impressões de viagem mais "brasileiro que nos tem aparecido", pois:

Raul não foi à Europa por diletantismo. Foi como brasileiro que quer se assegurar da injustiça que nos persegue e dificulta os passos, de ser ainda o Brasil um "país de selvagens".

E por isso Raul não voltou sofrendo da indecorosa moléstia de ter vergonha do Brasil e de haver nascido no Brasil.

O título Nós pelas costas indica não somente a capacidade de Raul de fazer bons trocadilhos, mas, principalmente, o que o autor procurava alcançar com o seu texto e com os seus desenhos: um amplo público da cidade, escrevendo sobre as suas impressões tanto da Europa quanto da cidade do Rio de Janeiro, portanto, uma escrita de 
si. O uso da gíria, tão comum entre os citadinos e somente compreensível em determinado tempo e espaço, explica hoje não sabermos defini-lo sem recorrer ao seu dicionário. A obra de Raul, para uma compreensão mais eficaz, precisa desse exercício hipertextual.

Raul Pederneiras viajou por parte da Europa no final de 1927, retornando ao Brasil em 1928. Partiu do Rio de Janeiro no dia 21 de outubro de 1927, a bordo do Satúrnia (O Paiz, 21/10/1927, p. 5), e parte da viagem virou coluna de jornal, sob o título "De terra em terra", publicado no Jornal do Brasil. ${ }^{5}$ A elaboração da coluna já era uma intenção de Raul Pederneiras, como comprova uma das cartas enviadas por ele a Octávio Tavares e Alberto de Lima, mantida na Fundação Casa de Rui Barbosa:

\section{Caros amigos,}

Em pleno oceano, há oito dias. O navio joga mais do que o Azeredo! Só consegui fazer isso que aí vai, sobre os tremeliques e giga goga do navio. Pode-se arranjar a página sob o título: Sobre as ondas - Em terra firme farei coisa mais aceitável - a história do enjoo é bobage, pois vou bem a bordo e o mesmo desejo que aconteça a todos vocês. (PEDERNEIRAS, 29/10/1927)

O autor - a bordo de um navio que balançava mais do que o Senador Antonio Azeredo, proprietário de periódicos como O Malho e Diário de Notícias - chegou à Europa em 9 dias, passando por Lisboa, Las Palmas e Vigo, percorrendo de navio a região do mar Mediterrâneo. Nesse caminho, passou por Marselha, Nápoles e Trieste, já no mar Adriático. Dessa última cidade, Raul embarcou para Bucareste de trem, viajando pela região dos Bálcãs, transitando pela Romênia (terra de sua esposa), lugoslávia e Grécia. No mesmo transporte, Raul Pederneiras foi até Paris, parando em Roma. E essas duas cidades foram as duas referências para o autor: a primeira negativa e a segunda positiva. De Paris, Raul seguiu para Boulogne Sur Mer, criticando muito a cidade do norte da França, de onde retornou ao Rio de Janeiro a bordo do Cap Norte (O Paiz, 18/01/1928, p. 4), em viagem de 17 dias.

\footnotetext{
${ }^{5}$ Foram localizadas três dessas cartas-crônicas, que depois seriam utilizadas no próprio livro Nós pelas costas. Ver: Jornal do Brasil, 04/12/1927, p. 9; 31/12/1927, p. 5; e 22/01/1928, p. 10-11.
} 
O livro não é um guia ou folheto de propaganda, nem um relato de viagem para futuros turistas. De fato, são pequenas notas soltas de viagem, muitas vezes fragmentadas e espaçadas, sem que siga uma linha coerente com início, meio e fim. Tal característica dificulta a própria compreensão do trajeto feito por Raul, como, por exemplo, nas passagens por cidades como Veneza e Nápoles. Há alguns desenhos espalhados pela obra. Uns nitidamente rascunhos sobre a população, suas vestimentas e seus hábitos, que possivelmente foram elaborados durante a própria viagem. Outros desenhos foram feitos posteriormente, ilustrando partes do texto, em formatos que lembram as imagens de sua obra clássica, Cenas da vida carioca, publicadas em periódicos ao longo de sua vida e em duas coletâneas, uma de 1924 e outra de 1935.

A narrativa também possui marcas posteriores de Raul, que intervém no texto dando a ele comicidade, o que é explicado pelo fato de o autor ter publicado fragmentos do texto nos jornais, bem como tê-lo transformado em palestra. Os chistes eram para a plateia/público leitor. Portanto, o livro era parte de uma estratégia de autoconstrução de Raul Pederneiras, através de performances públicas, que reforçavam a sua imagem de figura célebre da sociedade carioca do início do século XX, um "virtuoso". É forçoso lembrar que no que tange à performance, existe o seu neologismo, "performar", portanto, agir em público através de gestos, vestimentas e formas de falar, o que casa perfeitamente com a imagem de Raul e com a sua estratégia de produção de Nós pelas costas, um livro que não era necessariamente feito para ser lido, mas para ser apresentado a um auditório.

Tal estratégia narrativa também foi notada pelo padre Assis Memória (17/01/1931, p. 6), em carta endereçada ao próprio Raul, publicada no Jornal do Brasil, quando este afirmava ter gostado do estilo de "palestra simples" imposta ao livro. O fato de Raul Pederneiras ter tornado pública a carta de Assis Memória também é digno de atenção, para pensarmos na eficácia de sua estratégia narrativa. E, de fato, a viagem se tornou uma conferência, como demonstra a fotografia de uma dessas, ocorrida no Rotary Club. (Figura 2) 


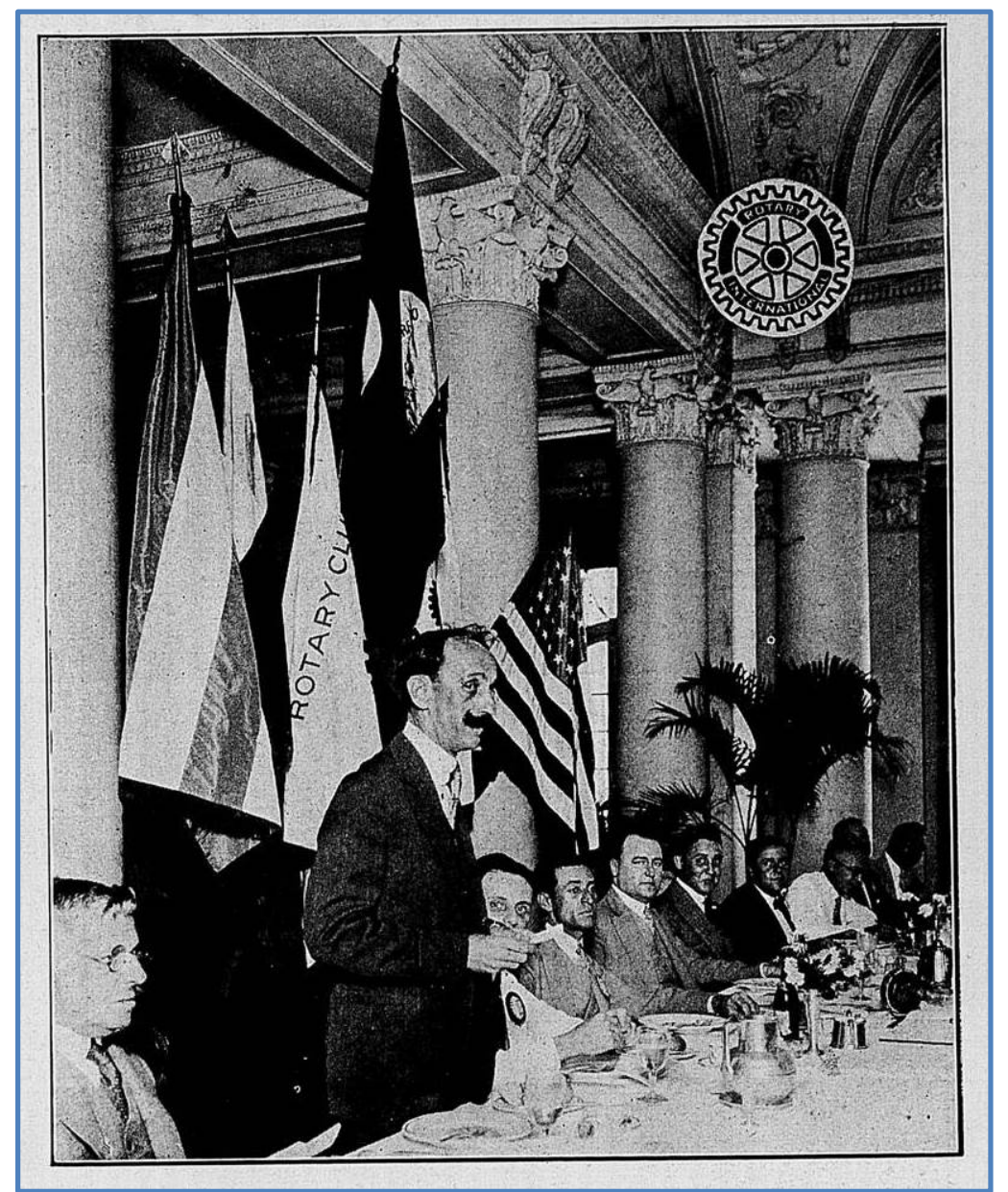

Figura 2. Legenda: Raul Pederneiras discursando em almoço no Rotary Club.

Referência: Revista da Semana. Raul no Rotary. 18/02/1928, p. 29-30. 1 fotografia. Acervo: BNDigital.

Parte da palestra de Raul foi reproduzida na Revista da Semana. Nela, Raul fala um pouco da viagem e de seu roteiro, de onde retiramos a informação de que passou pela Grécia, além de obtermos a informação do tempo de viagem de navio, de ida e de volta. Na reprodução da revista, Raul aborda o hábito dos europeus de manterem as suas barbas e bigodes, terminando a palestra falando do "sentimento belicoso" presente na Europa e da importância do Rotary Club na difusão dos ideais pacifistas, logo uma fala voltada para o seu público específico: “[...] A obra rotariana deve ativar a propaganda pacifista; a fraternidade só é vista nos livros e em raros monumentos, mas ainda não penetrou no coração dos homens." (PEDERNEIRAS, 18/02/1928, p. 29-30)

Não se sabe se a palestra foi ilustrada, mas esse era um hábito de Raul Pederneiras, que, por vezes, participava de conferências somente como caricaturista. De 
qualquer forma, na reprodução da Revista da Semana, o autor inseriu alguns de seus desenhos, que serviam especificamente para o seu público do Rotary (Figura 3).

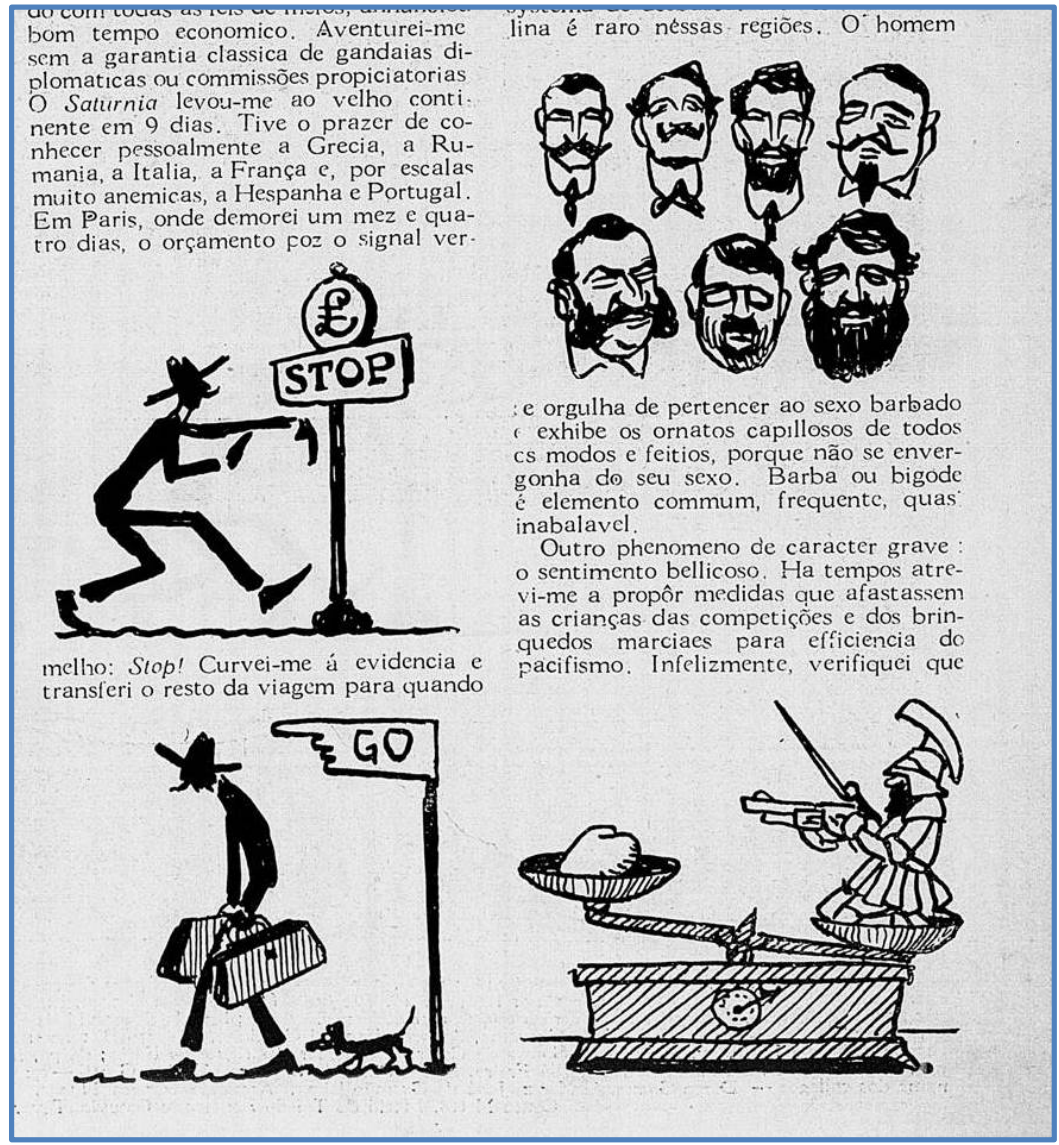

Figura 3. Legenda: Ilustrações referentes à palestra de Raul Pederneiras no Rotary Club. Referência: Revista da Semana. [Sem título]. 18/02/1928, p. 29-30. 3 ilustrações. Acervo: BNDigital.

As figuras que Raul opta por reproduzir na Revista da Semana não constam no livro. A última é especificamente feita para a plateia do Rotary ou para o leitor do periódico, pois é sobre o sentimento belicoso que Raul diz ter sentido na Europa. Uma representação contemporânea de Marte, deus da guerra na mitologia romana, que segura sua espada e aponta uma arma para um coração. Ambos estão em uma balança, na qual o peso de Marte é maior do que o coração. Logo acima, Raul ilustra alguns rostos de homens europeus, ostentando bigodes e barbas, um dos temas de sua palestra.

Já na primeira ilustração, Raul se autocaricatura andando pela Europa, onde gastou muitas libras do parco orçamento e, logo depois, cabisbaixo, retornando com as suas malas e o seu fiel cachorro para o Brasil. Sua autocaricatura, nesse caso, não é igual à da capa do livro 
(Figura 1). Sem os casacos e as proteções nos pés, Raul se desenha somente como uma sombra. Sabe-se que é o autor por conta do seu tipo esguio, dos seus bigodes e de seu chapéu de aba larga. Isso reforça a hipótese de que uma das leituras possíveis para o título do livro seja, simplesmente, a graça de ele ter-se colocado com o seu cachorro (sua visão humorística e de flâneur) rumo à Europa.

Tal observação ganha reforço quando analisamos a primeira imagem reproduzida no livro (Figura 4). Nela, Raul e o seu cão estão dentro do navio. Solitários, Raul e o amigo de viagem partiam à Europa, carregando somente o "porta-crayon" às costas. Nesse caso, também diferentemente da ilustração da capa, Raul recorre à técnica da sombra para se caricaturar. O célebre Raul partia para a Europa somente com o seu cão e o seu instrumento de trabalho.

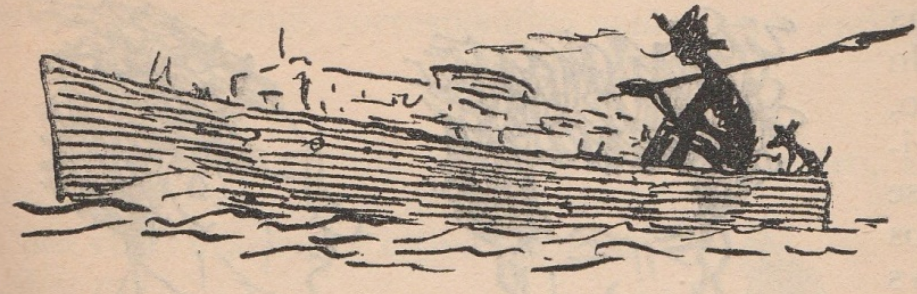
gens, tivemos o arrôjo de uma excursão pelo velho continente, com a ajuda de magro orçamento, cheio de muita vontade, mas quasi vazio de numerario. Faltou-nos o commodismo official das commissões folgadas, mas tivemos de sobra energia e vontade, alliadas ao trabatho intenso.

Quasi trinta lustros para vêrmos de perto o que conheciamos e apreciavamos de longe..

Figura 4. Legenda: Autocaricatura de Raul Pederneiras no livro Nós pelas costas. Referência: PEDERNEIRAS, Raul. [Sem título]. 1930, p. 5.1 ilustração. Acervo pessoal.

Aliás, os meios de transporte pelos quais trafegava Raul, o trem e o navio, Ihe deram sensações distintas com relação ao que via e ao que experimentou nas cidades por onde passava. O estar no navio, que lhe dificultava a escrita, permitia-lhe também conhecer o curioso comércio feito através de barbantes e cordas, nas cidades onde o transatlântico não aportava, como em Vigo. Navegando, Raul também tinha uma visão particular da cidade observada. Por exemplo, em Marselha, Raul analisava "à vista" 
flâmulas e bandeirolas nos telhados e fachadas. Pensou que a cidade estivesse em festa, o que era um engano, pois ele confirmou em Nápoles que se tratava do hábito de estender as roupas lavadas ao ar livre (PEDERNEIRAS, 1930, p. 8).

As flâmulas e bandeirolas idealizadas e as roupas ao ar livre observadas formam quase um contraponto entre ordem e desordem. Raul Pederneiras não descreve Nápoles como uma cidade porosa, onde há uma mistura e uma sensação de que a cidade nunca está terminada, tal como Walter Benjamin e Asja Lacis (1978, p. 167-173). Entretanto, o autor também tem uma visão particular dessa cidade, que comparava ao Rio de Janeiro. Sobre a paisagem de Nápoles, vista à noite, Raul dizia (1930, p. 8-9):

A chegada a Nápoles, ao anoitecer, impressiona agradavelmente; o aspecto é algo parecido com um trecho da querida terra carioca. Luzernas sobem e descem, acompanhando as sinuosas dos morros. Esse espetáculo mais atraente se tornou por estar o centro da cidade profusamente iluminado, destacando-se a cúpula da monumental Igreja de São Francisco de Paula.

A alegria da cidade italiana marca Raul. A sinuosidade das luzes dá um movimento especial a Nápoles, que o autor considerava uma cidade "cantante e alegre". E isso acabou repercutindo na forma como Raul encarou e interpretou os seus citadinos (1930, p. 60):

Já notamos que Nápoles é alegre e cantante. Procuramos cigarros. Abordamos um garoto de doze anos; o rapaz ofereceu-se para comprar; correu à tabacaria distante, trouxe o pacote de cigarros e o troco. Recebeu a gorjeta, fez a saudação fascista, risonho, e saiu a cantar pela rua, com uma voz de fazer inveja a muito Caruso indígena profissional.

O caminho de trem entre Trieste e Bucareste também permitiu uma experiência peculiar a Raul Pederneiras. A paisagem era totalmente diferente: predominava nesse momento as planícies monótonas de campinas e plantações. Já não eram mais as cidades iluminadas. A velocidade do transporte permitiu que Raul não somente percebesse as divisórias que indicavam as propriedades camponesas, como também observasse os 
próprios trabalhadores rurais. Afirmava Raul (PEDERNEIRAS, 1930, p. 12): “Essas terras, como um lençol verde, de onde há de surgir louro trigal, são cortadas por sinais divisórios, feitos com vegetação rasteira".

Ao mesmo tempo, o autor conseguia observar os seus trajes característicos, como o gorro afunilado de lã, a camisa bordada no peito e a cinta que cobria as calças brancas até os joelhos. Além de caracterizar as vestimentas, Raul Pederneiras também tentou reproduzi-las naquelas imagens que, talvez, tenha feito de olho, passeando pelos lugares, como é exemplificado pela figura que retrata um ambulante romeno, o seu vestiário e, especificamente, os seus sapatos (Figura 5).

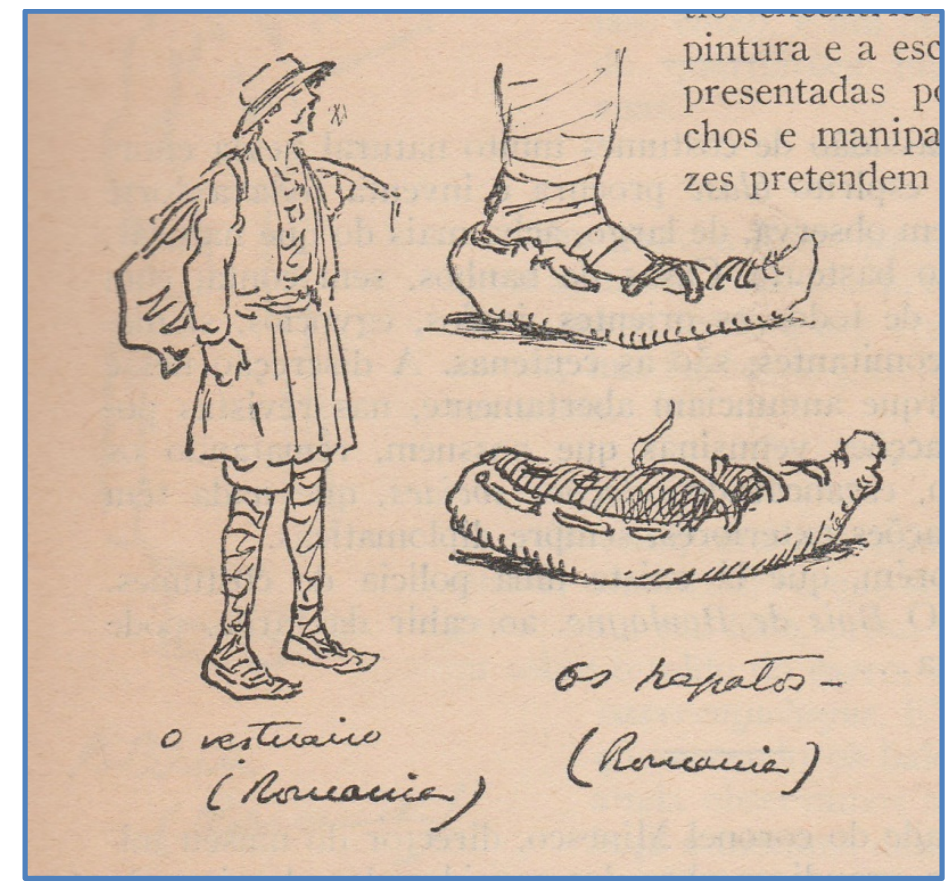

Figura 5. Legenda: "O vestuário (Romênia)" e "Os sapatos (Romênia)". Referência: PEDERNEIRAS, Raul. [Sem título]. 1930, p. 44. 1 ilustração. Acervo pessoal.

A experiência de Raul Pederneiras, porém, não se limitou ao que via da sociedade europeia. Não foi somente um exercício etnográfico ou uma leitura de observador das cidades pelas quais passou. A experiência nas cidades de Roma e de Paris foi importante para que Raul construísse uma interessante narrativa política sobre as transformações do pós-Primeira Guerra. Raul Pederneiras fez da sua viagem um momento de reflexão sobre 
o seu modelo de nação, tal como ocorria com outros intelectuais brasileiros da mesma época e que tinham vivido na belle époque (OLIVEIRA, 1990, p. 118-126).

\section{Roma e Paris: o caráter político de Nós pelas Costas.}

Como se percebe ao longo do seu livro, Raul viaja à Europa no período do entreguerras, o que explica a observação feita no Rotary Club de que as cidades pelas quais passou pulsavam o "sentimento belicoso". Ao longo de seu trajeto, Raul sentiu diretamente o clima tenso da Europa. Ainda na região da antiga lugoslávia, Raul Pederneiras assim descreveu a forma como as autoridades o interceptavam (PEDERNEIRAS, 1930, p. 13):

Interrompe-nos um guarda, ladeado por um soldado, para pedir o passaporte. Enche-nos de perguntas em francês, nome, idade, filiação, procedência e destino. Pergunta-nos ainda: "Fala várias línguas?”

- Não senhor, basta uma só contra uma ideia.

Como o homem não sabe o português, dá-se por satisfeito com a resposta.

Improvável que Raul tenha de fato feito o chiste com o guarda que Ihe solicitara o passaporte. Esse era o espaço ficcional do seu texto, que era possível e verossímil, uma vez que Raul Pederneiras encarnava a imagem do humorista. Foi uma saída cômica para o leitor e para a eventual plateia das suas conferências. Parte integrante da sua autoconstrução de sujeito "virtuoso", em que a sua excepcionalidade é o trocadilho. É provável que o público esperasse a brincadeira de Raul Pederneiras, e quanto mais audacioso ele fosse, mais espetacular pareceria em sua atuação como trocadilhista. Mesmo que seu público soubesse que não era verossímil falar em português na região da antiga lugoslávia, isso só seria possível através de uma figura de bufão como Raul Pederneiras.

Comprova-se o artifício literário de Raul quando comparamos a descrição desse mesmo momento publicado na coluna "De terra em terra", do Jornal do Brasil. Na cartacrônica, afirmava Raul (04/12/1927, p. 9): 
Em meio do caminho iugoslavo, num posto alfandegário com letreiros esquisitos e caracteres que lembram o nosso abecedário de pernas para o ar, um outro cavaleiro leu atentamente os dizeres do nosso passaporte para, no fim, indagar onde ficava o Rio de Janeiro.

- Fica tão longe que não vale a pena saber, foi a minha resposta, de que o homem não gostou, mas teve de ficar com ela, à falta de outra melhor.

No livro, a versão da história é diferente. O autor indicava que ao longo de toda a sua viagem pela região lhe foi solicitado o passaporte: “[...] penetra-se na complicada região iugoslava, onde, de estação em estação, aparecem soldados e funcionários a pedirem os passaportes. Não se pode pregar olho com essa frequência fiscal." (PEDERNEIRAS, 1930, p. 12). O verbo "pregar" é mais um trocadilho que Raul lança em seu texto, pois "dar o prego", na gíria carioca, significava "fatigar-se, desistir, afrouxar." Outros significados para "prego", segundo próprio Raul (PEDERNEIRAS, 1946, p.54), eram "mentira" e "casa de penhoras".

Não à toa, Raul Pederneiras (1930, p. 15-16) recorre ao seu uso para afirmar que havia ficado endividado na Itália, pois por lá a palavra "prego" era constantemente utilizada pelos seus interlocutores quando respondiam a um agradecimento. O autor testava as piadas que faria, buscando o melhor efeito humorístico, fosse ela para os leitores dos jornais ou para o auditório de uma conferência. De qualquer maneira, no caso da lugoslávia, o uso da palavra "prego" era para indicar que Raul Pederneiras não podia dormir ("pregar os olhos") e não podia ficar desatento com as autoridades.

Tal controle também foi sentido pelo autor na Itália de Mussolini. Segundo relata Raul Pederneiras, em Roma, alguns “camisas negra” o olhavam estranhamente por conta de seu chapéu preto de aba larga. Sua autoconstrução, como um personagem célebre da cidade, só tinha significado dentro do Brasil e para o público nacional. Segundo Raul (1930, p. 63), uma pessoa amiga o aconselhou cuidado, pois aquele era um distintivo dos oposicionistas, que o utilizavam nas províncias italianas e que, por isso, evitavam ostentar o símbolo na capital.

Ficamos suspeitos nos primeiros dias; A polícia pesquisou no hotel, examinando nossos papéis e bem depressa desapareceu a ameaça que nos cercava. Uma revista francesa, comentando esse fato, teve um interessante reparo: "Curieux pays ou le noir est orthodoxe dans la chemise et révolutionnaire dans le chapeau..." 
A interessante observação da revista francesa de que a Itália seria curiosa, pois era um país onde o "preto é ortodoxo na camisa e revolucionário no chapéu”, nos indica duas questões interessantes. Primeiro de Raul citar a revista francesa para mostrar ao seu público no Brasil que era conhecido na França, a tal ponto de sua aventura ser digna de uma nota em uma publicação estrangeira. Ser reconhecido na França era uma estratégia para reforçar a sua "virtuosidade", sua celebrização, no Brasil. Outro ponto é que essa citação nos faz pensar sobre a relação e a experiência de Raul Pederneiras em dois tipos de regimes diferentes na Europa do entreguerras: a Terceira República Francesa e o regime fascista de Mussolini.

Com relação à primeira questão, não conseguimos localizar o reparo da revista francesa feito ao caso ocorrido na Itália. Entretanto, encontramos algumas citações a Raul Pederneiras na imprensa daquele país. A primeira se deu logo em sua chegada a Paris, no jornal Le Gaulois, que informa (02/12/1927, p. 3):

M. Raoul Pederneiras, le distingué professeur à l'Université de Rio-deJaneiro et membre de l'Académie des beaux-arts de cette capitale, est arrivé à Paris, [?] compte faire un séjour prolongé.

En dehors de ses titres éminents, M. Raoul Pederneiras est le caricaturiste attitré des principaux journaux illustrés du Brésil.

Raul permaneceu, de fato, pouco mais de um mês na capital francesa. Interessante notar que o informativo o distingue como um professor da Universidade do Rio de Janeiro e membro da academia de Belas Artes, e só depois indicou que Raul também era caricaturista dos principais jornais ilustrados do país, o que é uma pequena inversão de todos os perfis que já circulam no Brasil nesse período.

Além dessa aparição no Le Gaulois, Raul também foi citado pela revista La Nature (Notre Nom, 01/03/1928, p. 228), que o comparava ao importante caricaturista Caran d'Ache, de quem Raul era um fã público, sendo uma de suas principais referências artísticas (PEDERNEIRAS, 15/05/1920, p. 5). A revista reproduziu dois onomatogramas de Raul Pederneiras, indicando a sua originalidade. A nota da revista francesa foi republicada pelo Jornal do Brasil, que a atribui a Victor Forbi, mantendo o texto em francês "[...] para não Ihe tirar o sabor do original" (JORNAL DO BRASIL, 17/12/1927, p. 6). 
Apesar de toda a recepção na Paris, indicando inclusive um pouco do seu circuito de relacionamentos sociais, como no caso de Jean Marie Victor Forbi, escritor e divulgador científico francês, a experiência de Raul na Itália não foi tão decepcionante para ele quanto a da França. Mesmo quando aborda o fascismo e o contratempo com os “camisas negra”, a Itália Ihe deu uma sensação de ordem, e Roma foi para Raul a cidade “idealizada”, enquanto Paris pareceu ser uma metrópole confusa, uma cidade que de “idealizada" passou a "real".

A Roma de Raul Pederneiras ilustrava perfeitamente o conceito de "cidadecapital". Se existe uma dimensão cênica na cidade, e seus objetos são obras de arte, Raul enxergava na capital italiana a cidade que Giulio Carlo Argan (1992, p. 205) pretendia manter viva, criticando a especulação imobiliária e os produtos manufaturados que descaracterizariam a antiga cidade. Raul ainda se moveu sobre as "[...] camadas das épocas sobrepostas como peixes na água, em profundidade e na superfície.”, antes que Argan considera a interrupção de Roma. Segundo Raul (PEDERNEIRAS, 1930, p. 36):

Quem sai de Roma e visita cidades de outros países, sente Roma em todas elas. Roma domina nos monumentos e nas manifestações múltiplas da arte legítima. Arcos triunfais, colunas comemorativas, obeliscos, fontes, aquedutos, muralhas, palácios, templos, tudo indica, em grande escala, que Roma antiga foi a inspiradora.

A fonte de inspiração de todas as cidades, Roma ostentava, na visão de Raul, o que era legítimo em termos de arte. Nesse caso, o autor está se colocando como o professor da Escola de Belas Artes. Cada mármore romano era uma camada da história da humanidade e deveria ser contemplada. Como faz o autor ao admirar por duas horas Moisés, de Michelangelo. "E demoraríamos mais se o funcionário da pequena igreja de São Pedro não avisasse que ia fechar o portão." (PEDERNEIRAS, 1930, p. 13) Seria como se a estátua, os templos, os palácios etc. falassem a Raul, através da sua monumentalidade, de um tempo passado e que representaria o máximo do que seria a arte.

Sentia-se Roma em todas as cidades, mas nem todas as cidades mantiveram Roma em si. No papel de autoridade, Raul Pederneiras apontava o modelo ideal da "cidade- 
capital" europeia, mas também nos deixava os rastros das suas próprias opiniões e concepções de cidade. A Roma de Raul mantinha a métrica e a rima da poesia, já a Paris adotaria os "ismos" modernistas:

É impossível falar das artes plásticas na Itália, sente-se a anemia profunda dos vocábulos para a expressão verdadeira do encanto. O preciso quinhão está hoje aumentado com a soberba galeria de arte contemporânea e, na parte histórica documental, com a extensa galeria Mussolini, recentemente acrescentada ao Capitólio. (PEDERNEIRAS, 1930, p. 44-45)

Raul cita muito Mussolini no seu livro. Porém, é importante destacar que não foi encontrada nenhuma fonte que indique que Raul Pederneiras tenha se filiado a alguma instituição fascista no Brasil. No máximo, o que foi encontrado foi uma suposta assinatura de Raul, publicada no jornal A Batalha, em favor da adoção do fascismo no país sob a organização da Ação Social Brasileira e de seu líder, J. Fabrino. Há 110 intelectuais que assinam a carta (Pela implantação do fascismo no Brasil, A Batalha, 30/07/1933, p. 1, 8 e 12). No Jornal do Brasil, periódico no qual Raul trabalhava, há algumas menções ao apoio de jornalistas cariocas à Ação Social Brasileira (Jornalistas cariocas opinam pela implantação do fascismo no Brasil, Jornal do Brasil, 03/08/1933, p. 8), mas não se comprovou o envolvimento desses autores citados para além dessas assinaturas de $A$ Batalha.

Ainda assim, nas notas de viagem de Raul Pederneiras, há certo encantamento com o fascismo e a ordem estabelecida na capital Roma. Como quase toda a intelectualidade das décadas de 1920 e 1930, Raul deve ter, de alguma maneira, se interessado pelas práticas autoritárias de solução à crise liberal. Ainda no início do seu livro, Raul Pederneiras (1930, p. 7) dizia que no navio os viajantes brindaram o aniversário da entrada de Mussolini em Roma, afirmando que: “Ergueram-se todos como um só homem; lancei uma saudação à Itália e à sua gente, correspondida com grande entusiasmo." Próximo à metade do livro, Raul Pederneiras colocou sua opinião a respeito do regime de Mussolini 
Em toda a Itália há o sentimento de ordem e de disciplina, nada observamos que denotasse constrangimento; sente-se que tudo lá está nos eixos e corre serenamente nos trilhos. De alguns oposicionistas ouvimos a confissão sincera de que o regime, embora não lhe seja simpático, deu ao país a normalização da vida e um ambiente expressivo de educação elevada, até então nunca visto, nem sentida. A obra do Duce trouxe magnífico resultado para a vida intensa e nobre desse grande povo. (PEDERNEIRAS, 1930, p. 27):

Já no final da obra, ao citar uma das frases de uma biografia de Mussolini, que aparecia nos jornais por conta da recente publicação - “Em política, nunca, jamais recebi dinheiro. Detesto os parasitas que se aproveitam das lutas sociais. Odeio os homens que a política enriquece." - Raul afirmou que se no Brasil, "terra de politiqueiros e de politicoides", fosse aplicado rigorosamente, poucos políticos conseguiriam escapar (1930, p. 57).

No que se refere às ilustrações, destaca-se que Raul (PEDERNEIRAS, 1930, p. 41) desenhou os milicianos e os guardas italianos e que na reprodução de pontos turísticos da cidade de Roma (quando, geralmente, colocava a representação de uma mulher à frente de um dos monumentos da cidade) Raul optou por inserir um camisa-negra à frente do Arco de Tito (Figura 6). Raul só recorreu à figura masculina em detrimento da feminina em mais duas ilustrações do livro: em Vigo e Veneza.

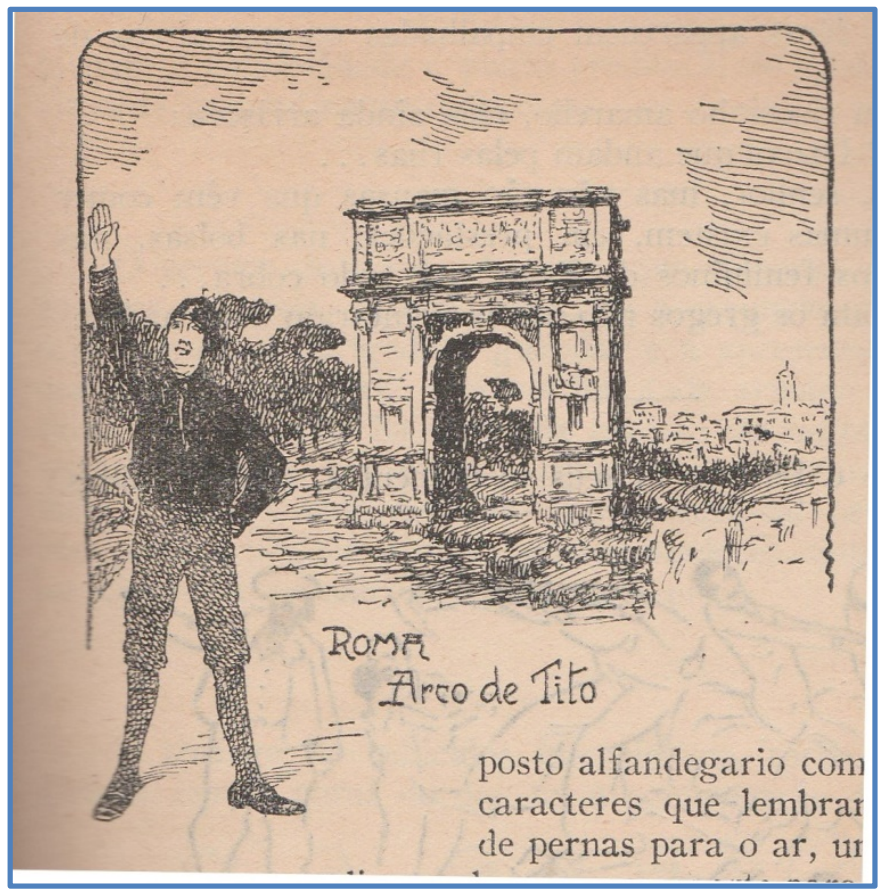

Figura 6. Legenda: "Camisa-negra em Roma".

Referência: PEDERNEIRAS, Raul. Roma - Arco de Tito . 1930, p. 17. 1 ilustração. Acervo pessoal. 
A imagem anterior é inserida na décima sétima página de Nós pelas costas. Ao juntar a arquitetura romana, usando como símbolo da conquista da Judeia por Roma, com a saudação fascista e a imagem do camisa-negra, o autor acabou por defender uma determinada visão da política do entreguerras, tornando-a pública, seja para os seus leitores ou para a plateia das suas conferências. Mesmo que consideremos que tal visão política tenha sido efêmera na vida de Raul Pederneiras, que tinha certa postura pragmática com relação à política (SILVA, 2014, p. 221), o autor associou a manutenção da arquitetura romana à ascensão do fascismo de Mussolini. A ordem era um caminho para a valorização/manutenção do passado, de uma civilização em crise.

É interessante observar que o relativo fascínio sofrido por Raul nessa viagem esteja associado à experiência na urbe. Como observa Mônica Pimenta Velloso, existia uma relação orgânica dessa intelectualidade boêmia com a cidade e com a rua. Era na rua, e na sua condição paradoxal, que se consolidava o artista moderno, que utilizava a ótica do humor para pensar a nacionalidade e o moderno (VELLOSO, 2015, p. 35-56). Nesse caso de Raul Pederneiras, a incompreensão com as transformações com a década de 1920 só fez sentido com a ida às cidades da Europa. Experimentar as capitais europeias era compreender o Rio de Janeiro.

Apesar de citar inúmeras cidades, o grande foco de contraponto de Raul Pederneiras se dá entre Paris e Roma. E se Roma o encantou por completo, Paris foi uma decepção. Mais adiante no livro (PEDERNEIRAS, 1930, p. 41), logo após retomar o assunto da saudação fascista, dizendo que em Roma a saudação estava consagrada, e para aqueles que gostavam dela ela era mais expressiva do que a continência marcial, Raul informa que, em contraposição, "Paris americaniza-se". Paris o decepcionou de início, quando ainda entrava pela cidade de trem (PEDERNEIRAS, 1930, p. 48-49):

Divisam-se, antes da chegada a Paris, pelo trem de ferro, muitas favelazinhas espalhadas à margem dos caminhos. Algumas praças da grande metrópole oferecem o espetáculo heterogêneo de casas de estilo ao lado de casebres que ainda residem prosaicamente, como se vê na Praça Saint André, onde o urbanismo está ainda no tinteiro dos projetos e das esperanças. 
Das “favelazinhas" dos arredores parisienses (comparação pejorativa com as casas populares do Rio de Janeiro), ao projeto urbanístico não iniciado, como na place SaintAndré des Arts, Raul não reconhecera em Paris a cidade-luz idealizada. A sua "cidadecapital” na prática foi diferente, mesmo que reconhecesse sua importância histórica. Apesar do olhar do voyeur, aquele que, segundo Michel de Certeau (1998, p. 170), “[...] sobe até lá no alto [do World Trade Center] foge à massa que carrega e tritura em si mesma toda a identidade de autores ou de espectadores", nessas duas cidades, Raul desce dos transportes panópticos em que se encontrava, saindo do trem ou do navio. Prendendo-se por mais algum tempo a Paris, Raul acabou por experimentá-la como um transeunte comum. E nessa experiência é que Raul compara as ruas das três capitais: Paris, Roma e Rio de Janeiro

Nas cidades italianas vimos invariavelmente, em qualquer rua, dois policiais fardados no serviço de vigilância, dia e noite. Em Paris parece que os policiais andam à paisana; fardados, além dos sinais de veículos, vimos dois somente, uma tarde, no boulevard dos italianos. Durante um mês e quatro dias não vimos outros, salvo no interior dos teatros. À noite transitávamos pelas ruas e pelos becos escuros, quase desertos, e sentíamos saudades do nosso esporádico guarda noturno, que, ao menos aparece e apita nos primeiros dias de cada mês... (PEDERNEIRAS, 1930, p. 26):

As ruas romanas pareciam mais seguras. Se compararmos às parisienses, até as do Rio de Janeiro pareciam melhores. Em Paris, não por acaso, a única rua onde Raul viu dois guardas foi no boulevard dos italianos. Enquanto Roma respirava a "legítima arte", Paris, apesar dos museus, produzia uma arte de pouco valor, com salóes e galerias vazias. Quando descreveu o Salão de Outono, por exemplo, Raul afirmou (PEDERNEIRAS, 1930, p. 44): “[...] A pintura e a escultura ali estavam representadas por todos os mamarranchos e manipanços com que os incapazes pretendem criar um estilo moderno, futurista, ou que pior nome tenha."

Paris aceitou as mudanças da Cosmópolis, enquanto a ordem italiana fazia manter viva a cidade idealizada. O fascismo italiano tinha alguma influência nisso, mas não era, em princípio, um determinante. Raul Pederneiras encontrou algumas respostas para os 
seus questionamentos ao sair do Brasil em sua aventura europeia. O passeio de Raul nas ruas europeias foi, também, uma experiência política na cidade.

\section{Considerações finais.}

Em Nós pelas costas Raul evocou duas modernidades vivenciadas em sua longa vida: a da belle époque, que já não exista na cidade-símbolo Paris, e a do modernismo da década de 1920, da qual era um grande crítico e que descrevia como produto de uma americanização. A grande comparação entre esses dois mundos se deu entre a arte e a arquitetura de duas capitais, e logo se dá na comparação das próprias cidades. Paris perdeu o seu encanto, enquanto Roma mantinha viva a sua história, a sua memória.

Se Michel de Certeau (1998, p. 171) afirma que o voyeur se aproxima analogamente das reproduções fac-similadas do urbanista, do cartógrafo e do administrador da cidade, pois também produz um artefato ótico sobre a cidade, e, por isso, deveria descer até o olhar do transeunte comum, Raul Pederneiras, ao descer da "costa" e encarar a cidade, baixa nos limiares dos seus praticantes ordinários. O autor, assim como os transeuntes nova-iorquinos de Michel de Certeau, escrevia a cidade, obedecendo "os cheios e os vazios do texto urbano". Mas, diferente da massa, Raul conseguia estabelecer uma leitura dessas duas capitais, construindo uma narrativa autobiográfica a partir de suas sensações, bem como uma versão política daquele momento vivido.

E tal narrativa serviu, ao final, para estabelecer o seu contato com a cidade do Rio de Janeiro. Ao término de sua obra, Raul Pederneiras exercitou o que o crítico Terra de Senna indicou em sua resenha sobre o livro: uma ode de paixão pelo Brasil.

Se, repleto de "nós pelas costas", Raul partiu de navio, observando Copacabana como o último ponto de visão da paisagem carioca, foi também Copacabana a primeira vista que recebeu o "beijo" dos seus olhos. Raul, o sujeito que visitou diversas cidades que só conhecia através dos livros, finalizava o trabalho com uma máxima que considerava "pieguice”, porém verdade incontestável: “É preciso viajar, correr outros mundos, privar com outros povos, para voltar com muito mais amor pela terra carioca." (PEDERNEIRAS, 1930, p. 70). 
E como em uma peça, das quais também foi reconhecido autor, Raul se desenhou despedindo-se do público (Figura 7). Uma autocaricatura encerrava o livro, Raul Pederneiras, em simples contorno de bico de pena, abre os braços para o leitor, esperando dele as palmas, ou o sorriso, em uma reflexão bem humorada de um momento de grandes transformações no Brasil e no mundo.

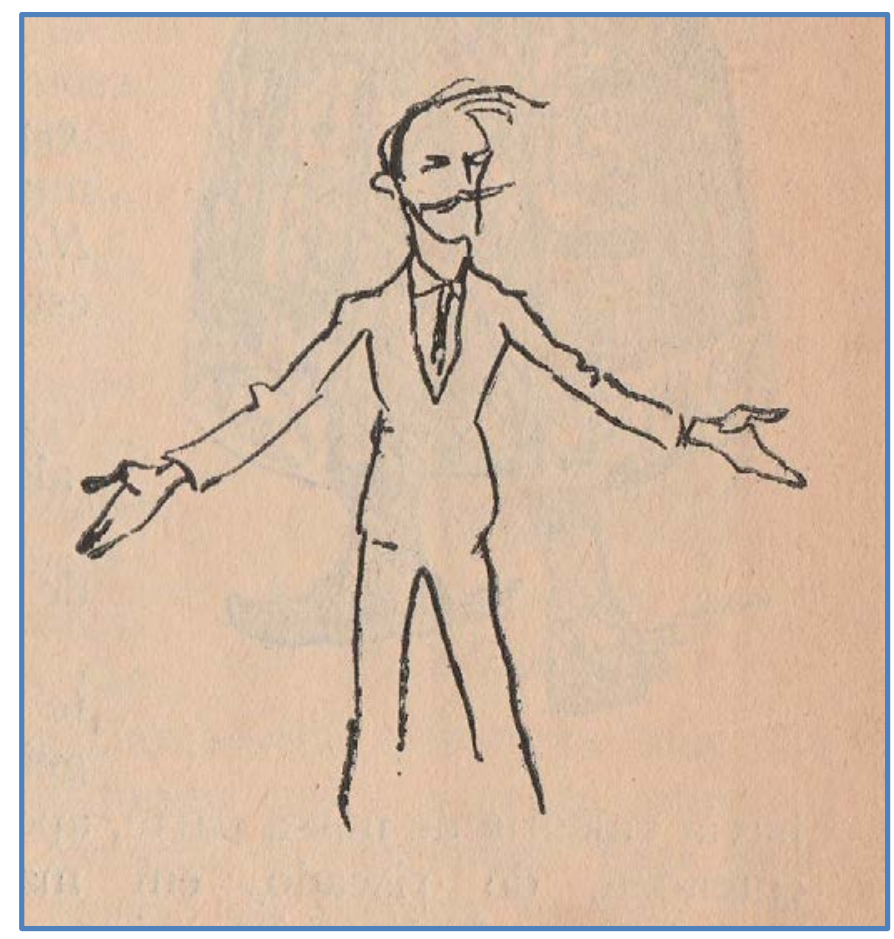

Figura 7. Legenda: "Raul Pederneiras parece reverenciar o leitor na última imagem do livro Nós pelas Costas". Referência: PEDERNEIRAS, Raul. [Sem título]. 1930, p. 70. 1 ilustração. Acervo pessoal.

\section{Referências}

ARGAN, Giulio Carlo. História da arte como história da cidade. São Paulo: Martins Fontes, 1992.

BENJAMIN, Walter; LACIS, Asja. Naples. In: BENJAMIN, Walter. Reflections essays, aphorisms, autobiographical writings. New York: Harcourt Brace Jovanovich, 1978, p. 167-173.

CERTEAU, Michel de. A invenção do cotidiano. Petrópolis: Editora Vozes, 1998. 
FORBI, Victor. Notrenom. La Nature, $1^{\circ}$ de março de 1928, p. 228.

LAHUERTA, Milton. Os intelectuais e os anos 20: moderno, modernista, modernização. In: COSTA, W.P; LORENZO; H.C (Orgs). A década de 1920 e as origens do Brasil moderno. São Paulo: Unesp, 2002.

LE GAULOIS, de 2 de dezembro de 1927, p. 3.

LIMA, Herman. História da caricatura no Brasil. 4v. Rio de Janeiro: José Olympio, 1964.

LILTI, Antoine. The Writing of Paranoïa: Jean-Jacques Rousseau and the Paradoxes of Celebrity. Representations, n. 103, p. 5-80, Summer 2008.

LILTI, Antoine. Reconhecimento e celebridade: Jean-Jacques Rousseau e a política do nome próprio. Tradução de Raquel Campos. Topoi: Revista de História, Rio de Janeiro, v. 15, n. 29, p. 635-649, jul./dez. 2014.

LUSTOSA, Isabel. Brasil pelo método confuso: humor e boemia em Mendes Fradique. Rio de Janeiro: Bertrand Brasil, 1993.

MACHADO NETO, Antonio Luís. Estrutura social da república das letras: sociologia da vida intelectual brasileira, 1870-1930. São Paulo: Grijalbo: Ed. da Universidade de São Paulo, 1973.

MEMÓRIA, Pe. Assis. Nós pelas costas. Jornal do Brasil, 17 de janeiro de 1931, p. 6.

METZNER, Paul. Crescendo of the virtuoso: Spectacle, Skill, and Self-promotion in Paris During the Age of Revolution. California: University of California Press, 1998.

NERY, Laura Moutinho. Cenas da vida carioca: Raul Pederneiras e a belle époque do Rio de Janeiro. 2000. Dissertação (mestrado em História) - PUC-RJ. Departamento de História. Rio de Janeiro, 2000.

OLIVEIRA, Lúcia Lippi. A questão nacional na Primeira República. São Paulo: Brasiliense; Brasília: CNPq, 1990.

PEDERNEIRAS, Raul. Carta de Raul Pederneiras para Octávio Tavares e Alberto de Lima, de 29 de outubro de 1927. Man. 1 fl. Loc.: AML PASTA: PEDERNEIRAS, Raul (AMLB/FCRB).

PEDERNEIRAS, Raul. De terra em terra. Jornal do Brasil, 4 de dezembro de 1927, p. 9.

PEDERNEIRAS, Raul. Nós pelas costas: notas de um caderno de viagem. Rio de Janeiro: Oficinas Gráficas do Jornal do Brasil, 1930.

PEDERNEIRAS, Raul. Raul no Rotary. Revista da Semana, 18 de fevereiro de 1928, p. 29-30. 
PEDERNEIRAS, Raul. Geringonça carioca: verbetes para um dicionário da gíria. Rio de Janeiro. F. Briguiet \& Cia, 1946.

SENNA, Terra de. Rua da Amargura. Diário carioca, 4 de junho de 1931, p. 6.

SILVA, Rogério Souza. Modernidade em desalinho: costumes, cotidiano e linguagens na obra humorística de Raul Pederneiras (1898-1936). 2014. Tese (doutorado em História) - Pontifícia Universidade Católica de São Paulo, São Paulo, 2014.

VELLOSO, Mônica Pimenta. Modernismo no Rio de Janeiro: turunas e quixotes. Petrópolis: KBR, 2015.

Recebido em 02/07/2016 Aprovado em 16/08/2016

Universidade do Estado de Santa Catarina - UDESC Programa de Pós-Graduação em História - PPGH

Revista Tempo e Argumento Volume 08 - Número 18 - Ano 2016 tempoeargumento@gmail.com 